\title{
Bloom's Taxonomy in Teacher's Pedagogy of Religious Education During Teaching Practice in Kenyan Secondary Schools
}

\author{
Jane Ciumwari Gatumu \\ School of Education, University of Nairobi, P0 Box 30197-00100, Nairobi, Kenya
}

\begin{abstract}
The research from which this paper is derived examined levels of Bloom's taxonomy displayed by secondary school students during their Religious Education lessons by teachers on teaching practice. Sixty teachers on their teaching practice for three months were observed as they presented their Religious Education lessons to these students. The key objectives of this investigation were: to: establish students' levels of the taxonomy displayed; examine the methods and instructional resources the teacher used to address these levels of the taxonomy; determine the level of students' participation as they manifested different levels of the taxonomy and finally explore how the students' performance was related to the student's levels of the taxonomy. Data was collected through the use of an adapted teaching practice standardised observation schedule of the University of Nairobi. Each of the sixty students was observed six times by the researcher and two research assistants were trained on what to focus on during their observations. A documentary analysis schedule was used to access the students' schemes of work and lesson plans to identify the various taxonomy levels students were expected to achieve. By applying content analysis, guided by themes arising from the objectives, to the records of observation and summaries from the documents accessed, a thick description was written. Using descriptive statistics, the various levels of the taxonomy were tied to the teachers' performance of their teaching practice exercise. The findings emerging showed that the most popular levels were at remembering, understanding and applying and the teachers' performance was lower than that of the teachers whose students had analysis, evaluation and synthesis skills. This could be explained by the fact that students' levels of the taxonomy tended to depend on the number of teacher's levels of engagement with the taxonomy in the student's learning process. This led to the conclusion that students become what their teachers are. The study recommends revisiting the teacher's training pedagogy to be geared more towards enhancement and promotion of analysis, evaluation and creating skills of the taxonomy.
\end{abstract}

Keywords: pedagogy, planning, taxonomy level, learning, teaching

DOI: $10.7176 / \mathrm{JEP} / 12-10-08$

Publication date: April $30^{\text {th }} 2021$

\section{Introduction}

Teaching practice provides student teachers with opportunities to display the interaction of theory and professionalism in a live classroom experience. It is in the classroom that the teacher interacts both formally and informally with the students through implementing that which has been schemed and planned for achievement. This is possible because, through pre-teaching practice encounters, the student teachers acquire knowledge, skills, values and competencies to empower them to be effective performers in the teaching and learning process (Parveen \& Mirza, 2012).

One key focus of pre-teaching practice experience is on the use of Bloom's and Anderson's Taxonomy's frameworks (Chandio et al., 2016). Bloom's taxonomy (1956) as revised by Anderson (2001) has provided frameworks upon which teachers make decisions on the direction their classroom pedagogy is implemented. The framework when well used ties the three key aspects of instruction: planning, teaching and assessment, making a whole. Thus, the framework enables the teacher towards being effective in making the students be what they should be by planning, teaching and assessing instruction being implemented.

Bloom's taxonomy is about spelling out the expected outcomes the learner has to acquire through interacting with given content. The outcomes are in six levels running in a continuum from the lowest being remembering, then understanding followed by applying and moving to the higher domains of analysing, evaluating and finally creating, with the highest being dependent on the lowest. To this extent, the teacher has to develop and apply mechanisms to ascertain that this is achieved by the students being what they should be if the teaching is student-oriented for them to be and become.

Hackathorn et al. (2011) researched a multi-dimensional training system evaluation using Bloom's taxonomy. They classified the learning objectives of a training programme using Bloom's taxonomy and then examined them to predict learners' performance. They then used the attained results to do a comparison with learners' reactions. The findings showed that learning objectives were good predictors of learner's performance, compared to learners' reactions and that a teacher cannot ignore them when considering the pedagogy to employ for students to learn.

Making cognitive objectives part of classroom communication is a teacher's responsibility. To Steel (2012), 
the six hierarchical learning levels as examined by Bloom should be ensured through various applications and adaptations for effective classroom communication. Hence, the current researcher was concerned with how well the student teachers during teaching practice paid attention to them and whether there is a difference in their performance based on these levels.

Parveen \& Mirza (2012) using both qualitative and quantitative methods, considered the types of cognitive processes that learners may undergo through their learning process. The research used 81 bachelors of education student teachers and six heads of the cooperative schools that facilitated the internship programmes. Data was gathered through interviews and the three-point Likert scale. The results of the study showed that the student teachers take an internship as a real chance to improve their skills in a real school environment and that internships are crucial as they affect the performance of student teachers. The student teachers were positively influenced by Bloom's taxonomy for making instructional decisions. However, it emerged that their focus was more on low levels of the taxonomy and thus recommended the use and integration of Bloom's taxonomy to suit the different student teachers who had diverse ways of teaching and learning the levels of the taxonomy. Similarly, in separate secondary schools, Chandio et al. (2016) examined the prevailing conditions of the English subject assessment practices by using Bloom's taxonomy. They found that there was too much reliance on remembering, understanding and application, and the assessments missed assessing analysis, evaluation and creativity. To them this was a reflection on how the teaching-learning process had been handled as much of the focus was examination-oriented marked by the teacher's authority over the content. Also, Rupani \& Bhutto (2011) had conducted a qualitative study to evaluate normal teaching based on Bloom's taxonomy in a secondary school. The sampling had 30 students, whereby, ten students were interviewed and twenty were chosen for focus-group discussions. The results showed that the teaching was more teacher-centered than learner-centered. This was because teaching approaches included remembering and rote learning, with little concern for comprehension and other higher levels.

The role of the teacher's pedagogy in designing educational programmes that address the different levels of Bloom's taxonomy is supported by Ertmer et al. (2011) whose research on student-content interactions in online classes supports the role of a teacher's methodology in the level of skill that arises in the students. Their research revolved around the role of question prompts in enhancing higher-level engagements with course content. The research investigated the relationship between the types of questions and students' subsequent responses. The findings supported the hypothesis that questions placed at Bloom's taxonomy higher level, facilitate higher-level student answers. This raises the central role played by the teacher's selection of classroom pedagogy to enhance students' levels of thinking.

Ene and Barna (2014), in their analysis of an RE curriculum, concluded that the RE teacher has the responsibility of ensuring that every individual student develops skills needed for life in the society intending to make them be independent members of society and have the initiative to make life in society better.

The study by Sanabria-Ríos \& Bretz (2010) determined the relationship between educators' cognitive expectations about RE and the construction of examination questions. The examination questions for the yearlong general religious study sequence were categorised using the Bloom's taxonomy and expanded methodology for evaluating general examinations. The results showed that there was a relationship between learning objectives and examination questions. This tends to suggest that incorporating conceptual assessment needs, teachers have to look into what objectives they desire for their students. Ene and Barna (2014) argue that Bloom's scheme does not just exist, it is embedded in the totality of classroom instruction to which the RE teacher must be committed to claiming success to critical pedagogy at work.

Guided by Bloom's framework, Eslami (2016) formulated her model to use in assessing critical thinking in $\mathrm{RE}$ in Scotland. Her concern was whether RE as a subject addresses critical thinking which has aspects of Bloom's taxonomy. Her research established that relevant RE documents lacked a clear focus of critical thinking and that teachers had not developed a pedagogy that enhanced it as it was not clear to them what it is. However, she agrees on the aspect that the low-level skills are significant in laying a foundation for the more advanced skills of metacognition.

Tabriz and Rideout (2017) advocate for a critical pedagogy that ascertains that high levels of thinking are attained. They argue that teacher-focused methods like lecturing, demonstration and reading a text tend to enhance low levels of thinking as opposed to liberational methods which facilitate higher levels of Bloom's taxonomy. They spell it out that liberational methods enhance students' confidence and thus freedom to freely express themselves is a factor of critical thinking. Such methods include discussions, debates, questions from both the teacher and students. In such circumstances, the teacher organizes for open-ended activities which many a time demand high-level teacher creativity and insightfulness. Ene and Barna (2015) support this as they argue that the RE teacher must work towards motivating the student to have the initiative to create things and to be independent. Kjeldsen (2019) argues for an analytical skills approach that deepens students' understanding of religion in pluralistic and secular environments. To this extent, the RE teacher must have professional and use pedagogical skills to ascertain this accomplishment. 
This does not imply undermining memory as a power, initiated by rote learning. This is supported by Chambers (2010) in his advocacy for engaging students in the promotion of memory for foundation content that initiates constructive learning and involvement in a RE lesson. To Chambers (2010), memory has been undermined and it should be cherished as a foundation and formative skill that ensures that the teacher is active other than being a facilitator. However, where the RE teacher is not guided by Bloom's framework, then students are made to be passive and not get engaged in critical pedagogy. The application of Bloom's taxonomy in RE becomes a matter of concern in that decision-making leading to improved practice in the teaching-learning process can be made. The current paper is about how those under training to be RE teachers apply Bloom's taxonomy in their classroom pedagogy during teaching practice.

Religious Education is one of the subject areas for teachers on teaching practice where they can investigate how well they can affect Bloom's taxonomy. In 2019 there were 156 students' teachers of the University of Nairobi, School of Education, teaching Religious Education either under Christian Religious Education or Islamic Religious Education. Religious Education's (RE's) goal in the curriculum is to contribute towards students' critical thinking and therefore the teacher needs to adopt an appropriate pedagogy to attain this expectation. This study is about whether teachers on teaching practice take time to enhance Bloom's cognitive skills in their teaching. Does the teaching of Religious Education contribute towards teachers working towards the attainment of the six levels of the taxonomy? A sample of 60 teachers was randomly selected from this population of 156 to take part in the investigation.

The study was guided by the objectives to:

- Examine Bloom's levels of thinking displayed in RE lessons.

- Explore methods teachers use to promote different levels of thinking.

- Examine resources teachers of RE use to enhance different levels of thinking in their lessons

\section{Research methodology}

This research was done using a descriptive survey research design employing a qualitative approach as it allowed the researcher to assess the scenes of operation, the teaching practice schools of the 60 students randomly selected from a population of 156 teachers. Each of the teacher's documents and life lessons were assessed using agreed criteria derived from Bloom's taxonomy framework. This took place in 12 weeks of teaching practice in 2019.

The researcher and her two research assistants used a documentary analysis form showing aspects of the scheme of work and lesson plan with a focus on the six levels of thinking postulated by Bloom (1956) and revised by Anderson (2001). The concern was whether any of these documents had factored in aspects of Bloom's taxonomy which formed the planning for teaching. From the scheme of work and the lesson plan, the points of focus were the objectives, learning activities and learning resources/references. The researcher and the two research assistants would record against each student the different skills for the specific lesson plan derived from the scheme of work. The criteria to guide the documentary analysis was derived from Anderson's model where the key verbs for various levels of thinking were outlined in terms of teacher's promotion of pedagogy.

It was only after this pre-teaching stage; the researcher and her two assistants were able to observe life lessons. The focus here again was levels of thinking emerging in the various parts of the lesson: introduction, development and conclusion and what learning activities were the students engaged in and the instructional resources to capture students' imagination. At the end of the lesson, a score out of 100 was given by the researcher and her two assistants on how well the six levels of thinking were demonstrated.

To determine the performance of the teacher, the score was pegged on his/her level to enhance Bloom's taxonomy in the teaching of RE. The level of enhancement was derived from the planning stage of making the scheme of work and lesson plan and the presentation of the lesson through the use of diversified learning activities and instructional resources. The number of thinking skills enhanced in a lesson were considered for a score out of 100. A mean score was calculated for each of the 60 students from the scores of the researcher and her two research assistants.

The template for scoring was as follows:

Four levels of thinking and above: Excellent $70 \%$ and above

Three levels of thinking: Good $60-69 \%$

Two levels of thinking $\quad 50-59 \%$

One level of thinking $\quad 40-49 \%$

\section{Research findings and discussion}

\subsection{Overview of the levels of Bloom's Taxonomy found in the study group}

Table 1 shows how the teachers tied their objectives to the different levels of Bloom's taxonomy as derived from the schemes of work and lesson plans. 
Table 1. Teachers' Objectives and the Levels of Thinking

\begin{tabular}{|c|c|c|c|}
\hline \multirow[t]{2}{*}{ No of objectives } & \multicolumn{2}{|c|}{ No of teachers } & \multirow[t]{2}{*}{ Levels of thinking } \\
\hline & $\mathbf{F}$ & $\%$ & \\
\hline 4 & 4 & 7 & $\begin{array}{l}\text { - Recalling, Comprehending, } \\
\text { - Application } \\
\text { - Creativity }\end{array}$ \\
\hline 3 & 41 & 68 & $\begin{array}{ll}\text { - } & \text { Recalling } \\
\text { - } & \text { Comprehending } \\
\text { - } & \text { Application }\end{array}$ \\
\hline 2 & 11 & 18 & $\begin{array}{ll}\text { - } & \text { Recalling } \\
\text { - } & \text { Comprehending }\end{array}$ \\
\hline 1 & 4 & 7 & - Comprehending \\
\hline
\end{tabular}

Table 1 shows that most of the students $(n=45)$ had three objectives in both the scheme of work and the lesson plan. These objectives were hierarchically stated from low to high levels of Bloom's taxonomy. The 11 with two objectives had also hierarchically stated them. For instance, three students teaching the same topic, "Jesus' teaching on watchfulness" had the following objectives:

Student 1

At the end of the lesson the learner should be able to:

- State characteristics of watchfulness

- Describe what Jesus taught on watchfulness

- Explain why Jesus taught on watchfulness

- Discuss ways in which Christians in contemporary society can be watchful.

Student 2

At the end of the lesson, the learner should be able to:

- Define the term watchfulness

- Describe what Jesus taught about watchfulness

- Explain the importance the relevance of Jesus' teaching on watchfulness to contemporary society

Student 3

At the end of the lesson, the learner should be able to:

- Explain what Jesus taught on watchfulness

- $\quad$ Describe ways in which it is relevant to contemporary society

What this seems to show is that the students were able to apply Bloom's framework to facilitate their planning and this provided directly to them as recommended by Chandio, et al (2016). These three students had the lesson's content presented in stages, moving from simple to complex as they applied the principle of known to the unknown.

From the documentary analysis of these lessons, the researcher noted that the three teachers had a deliberate move to allow students to begin to participate in what seemed to be the known with an effort directed towards the skill of understanding. In this case, understanding depended on the recalling, while the application depended on the understanding. Being able to do this shows the teacher's ability to ascertain effective communication in class (Steel, 2009).

The classroom observation of life lessons of these three students displayed that more time was allocated to the remembering skill. The students were expected to remember what had been the lesson's highlights. Even at the lesson conclusion, the take-home assignment tended to address memorizing an issue or issues raised in the course of the lesson presentation. This may be explained by what Eslami (2016) gives in her analysis of RE teaching in Scotland where she argues that teachers may lack the critical skill and are therefore unable to teach it to their students. Also, this focus on remembering may be due to the way the RE examinations are set as they emphasize recalling information (Sanabria-Rios and Bretz, 2010).

\subsubsection{An example of higher-level skills employed in a Christian RE lesson}

It is important to note that a few teachers made a deliberate move to engage students in high-level skills where the students would engage in the discussion using more heuristic and critical methods to display skills like creating, evaluating and analysis. For instance, a teacher observed in a life lesson teaching the topic "Jesus teaching on persistence in prayer" had the following objectives:

At the end of the lesson, the learner should be able to:

- $\quad$ Highlight what Jesus taught about persistence in prayer

- $\quad$ Discuss the importance of Jesus' teaching on persistence in prayer.

- $\quad$ Perform a scene to show Jesus' relationship with the widow 
For objective three to be achieved the teacher had prepared a 10 minutes drama where students acted out the different roles depicted in the parable. The researcher noted the innovation and imagination of the students as they acted in the scene. The coordination to have each student play a role to contribute to the theme of persistence in prayer was displayed in a very remarkable way. One needs to note that all the levels were merged and depended on each other to end up with a team of students who were heuristic, creative, critical and insightful, manifesting ingredients for critical pedagogy. One clear thing was that there were moments when the teacher would refer to lower skills to promote higher-level skills. This teacher ended up scoring highly because the involvement of the students was extremely high and all levels of Bloom's taxonomy were achieved in this lesson. This seems to be in agreement with Ene and Barna (2014) who argued that there must be an integration of all mental processes to make the student complete in their being.

\subsubsection{An example of higher-level skills employed in an Islamic RE lesson}

An Islamic Religious Education lesson whose topic was "Main celebrations in Islam" was observed. The objectives of the lesson were:

At the end of the lesson, the learner should be able to:

- $\quad$ Define the term celebration

- $\quad$ Describe three key celebrations observed by Muslims

- $\quad$ Explain the importance of these celebrations

- $\quad$ Prepare a diagram/poem to show the importance of one celebration to Muslims

This was in a class of 30 students. The teacher put the students into five groups. It was impressive the way members of the group displayed their skills of listening to one another, creativity, organization, collaboration as they did their drawing and composing. Multiple intelligences emerged in this activity and the work was finally displayed with a lot of satisfaction from the students at what they had achieved. The students appeared motivated by the teacher as recommended by Ene and Barna (2014) on how the RE teacher should behave towards their students.

What emerges from these two examples is that higher levels of thinking demand a teacher who is creative and who sees a student beyond the people who take examinations. The teachers let the students' minds be free to explore and express themselves. This means that the students may need their self-confidence and feeling of respect enhanced. Further, this may mean that the student must be treated as a unique individual capable of something unique. This agrees with Tabriz and Rideout (2017) who attach levels of thinking to teacher's pedagogy for the individual student.

\subsection{Bloom's taxonomy and methods of teaching RE}

A teacher's pedagogy is about organising one's behaviour to facilitate students' learning. This behaviour is about what the student does towards his/her learning facilitated by the teacher. Learning activities emanate from teaching methods. Both the scheme of work and lesson plan had a column for the teacher to indicate the learning activities the students would be engaged in during a specific lesson. Table 3 shows the number of learning activities displayed for the lessons which were observed life by the researcher.

Table 2 shows the number of learning activities displayed in a lesson.

\begin{tabular}{|l|r|c|}
\hline No of activities & \multicolumn{2}{|c|}{ No of students } \\
\cline { 2 - 3 } & F & \multicolumn{1}{|c|}{$\%$} \\
\hline 4 & 11 & 18 \\
\hline 2 & 12 & 20 \\
\hline 1 & 20 & 33 \\
\hline None & 11 & 18 \\
\hline
\end{tabular}

The stated learning activities in both schemes of work and lesson plans were rather minimal. Many students $(n=31)$ indicated one or two learning activities for all parts of the lesson. Of the 60 students, 23 had more than two activities in their schemes of work and the lesson plans. Those teachers with one learning activity would insert it only at the introduction and at other parts of the lesson nothing would be shown. This may imply that the stated single learning activity is expected to serve the other sections too. An implication arising for this may be that teachers do not connect the objectives to methods of teaching. Consequently, they do not tie the expected taxonomy levels to their classroom pedagogy. To many of them, their key learning activity was question and answer which they ended dominating and not giving chances to students to ask. Also, the questions posed would be more on remembering, understanding and application and hardly any question on evaluation and creativity. Thus, from their planning, they did not aspire to the highest level of creativity where the students would be transformers of information as implied by Tabriz and Rideout (2017).

This area of learning activities may suggest that it is a component of planning not given sufficient time. A major implication here may be that teachers do not seem to know where to get learning activities from. Learning 
activities emanate from methods of teaching/learning. Teachers with minimal learning activities tended to use transmission methods meant for laying the foundation (Gatumu, 2020; Groenewegen, 1993). In these methods, the teacher tended to be authoritative and content-oriented while students were mere receivers of information. There were instances observed when the teacher held a notebook which he/she kept on referring to as his/her memory bank. Hardly were questions asked to specific students as much of the organization was not individual student-oriented. They lacked the focus that several learners have varying capacities in their learning abilities requiring innovative ways to teach for the benefit of all learners in an inclusive classroom setting displaying the need for support and care (Chambers, 2014)

\subsection{Bloom's taxonomy and Learning resources for $\mathbf{R E}$}

The instructional resources in the schemes of work and lesson plans were accessed as a way to assess the mind of the teacher to view his/her perspective of the student he/she planned to engage in transformative activities. From the documents accessed, it emerged that there was minimal attention given to instructional resources. The basic given references and resources were the bible/Quran and the class textbook. These were mainly used for sourcing the lesson's content. Those resources which can arouse the attention and curiosity of the students were hardly existent. The writing board, an obvious resource was utilized very well to capture the lesson highlights for students to remember. This was particularly noticed at the lesson's conclusion when the teachers would end the lesson with a summary of the lesson on the writing board or a chart. The purpose of this was to help the student remember the lesson's focus.

A few teachers tried to use some relevant newspaper cuttings and magazine pictures of relevance. To Godfrey (2012) and Olanyika (2016), instructional resources make learning interesting and facilitate understanding of difficult concepts and inform and guide teachers in their enhancing of the lesson's objectives. What emerged was that where the teacher used a captivating resource the student paid attention in readiness to respond to the images presented to them. The kind of questions posed by the teacher on the image under focus determined the level of thinking the teacher was out to enhance. On low level thinking it was more of what the resource was about and not taking the student to the next level of attaching meaning to what they saw. For the teachers who engaged students more with what they displayed it was noted that there was something more than stating, they could even bring out similar occasions not necessarily displayed by the image under focus and thus making creativity emerge. Simiyu (2007) suggests that student attention is sustained through the use of instructional resources which contribute to better achievement of learning outcomes. Wangari and Gatumu (2014) and Tuimur and Chemwei (2015) declare that instructional materials are critical ingredients in learning RE to make students be problem solvers of day-to-day concerns.

\subsection{Bloom's Taxonomy and teachers' performance}

Each of the 60 research participants received a score after his/her RE scheme of work, lesson plan and life lesson assessed by the researcher and her two research assistants. This score is about the levels of thinking he/she enhanced in the planning and teaching RE. Table 4 shows how these 60 teachers performed.

Table 4: Teachers' performance in enhancing Bloom's taxonomy

\begin{tabular}{|l|l|l|l|}
\hline \multirow{2}{*}{ No of levels of thinking } & No of teachers & \multirow{2}{*}{ Mean score } \\
\cline { 2 - 4 } & F & \% & \\
\hline 4 & 4 & 7 & 61 \\
\hline 3 & 41 & 68 & 68 \\
\hline 2 & 11 & 18 & 57 \\
\hline 1 & 4 & 7 & 44 \\
\hline
\end{tabular}

What is on Table 4 demonstrates that Bloom's taxonomy feature in the teaching of Religious Education. With four teachers scoring $81 \%$ is an indication that the teaching of Religious Education as a realm of meaning and form of knowledge has a contribution to give towards developing the student's potential of being the kind of persons they should be in society. It is noticeable that much of the teaching tends to focus on the foundation skills as raised by Eslami (2016). This must be understood that most of the teachers emphasized teaching for examination as these are the skills tested at national examinations (Itolondo, 2012).

\section{Conclusions}

It is important to note that the teachers on teaching practice for RE perceived students' levels of Bloom's taxonomy to be significant as they had a role to play in the classroom. How to make them play that role became another defining moment that was affected by external factors and personal characteristics of the teacher. Making students get motivated by examinations is important, however, this narrowed the focus of Bloom's taxonomy to be on rote learning pedagogy, limited to remembering, understanding and application. This study is calling upon teachers to view Bloom's taxonomy as facets of life that extend even after examinations. It also emerges that the level of teacher's motivation has to be put into the task as it is about as it has to be geared 
towards what potential of the student should be developed as the life of students is more than examinations. What arouses the teacher's creativity becomes a matter of concern in that the student becomes the kind of person the teacher goes out to help recreate for the present and future life.

\section{References}

Anderson, L. W. and Krathwohl, D. R., eds.(2001), A taxonomy for learning, teaching, and assessing: A revision of Bloom's taxonomy of educational objectives, New York: Longman

Chambers, M. (2010). Memory in the Religious Education Classroom. Journal of Religious Education 58 (2). https://core.ac.uk/download/pdf/286460595.pdf

Chandio, M. T., Pandhiani, S. M., \& Iqbal, S. (2016), "Bloom's taxonomy: Improving assessment and teachinglearning process", Journal of Education and Educational Development, 3(2), 203-221.

Ene, I., \& Barna, I. (2015). "Religious education and teachers 'role in students' formation towards social integration", Procedia-Social and Behavioral Sciences, 180, 30-35.

Ertmer, P. A., Sadaf, A., \& Ertmer, D. J. (2011), "Student-content interactions in online courses: The role of question prompts in facilitating higher-level engagement with course content", Journal of Computing in Higher Education, 23(2-3), 157.

Eslami, R.M. (2017), Approaches to critical thinking in religious education in Scotland: analysis of teachers' accounts and curriculum documents in non-denominational and Roman Catholic sectors. A PhD thesis at the University of Edinburgh

Gatumu, J. C., \& Ndungu, A. W. (2014), "Religious education programmes and moral development of preschool children in Nairobi county", Kenya. Southeast Asia Early Childhood Journal, 3, 24-35.

Gatumu, J. C. (2020), Teaching of Religious Education in Kenya secondary schools, Evangel Publishing House, Nairobi, Kenya. ISBN: 9966-20-320-6

Groenewegen, T. G. (1993), Subject methods in religious education. Nairobi: Lectum Publication Ltd

Hackathorn, J., Solomon, E. D., Blankmeyer, K. L., Tennial, R. E., \& Garczynski, A. M. (2011), "Learning by Doing: An Empirical Study of Active Teaching Techniques. Journal of Effective Teaching, 11(2), 40-54.

Itolondo, W. A. (2012), The role and status of Christian religious education in the school curriculum in Kenya", Journal of Emerging Trends in Educational Research and policy studies, 3(5), 721-729.

Kjeldsen, K. (2019), “A study-of-Religion (s)-Based Religion Education: Skills, Knowledge, and Aims”, Center for Educational Policy Studies Journal, 9(4), 11-29.

Parveen, S., \& Mirza, N. (2012), "Internship program in education: Effectiveness, problems and prospects", International Journal of Learning \& Development, 2(1), 487-498.

Rupani, C. M., \& Bhutto, M. I. (2011), Evaluation of existing teaching learning process on Bloom's Taxonomy. International Journal of Academic Research in Business and Social Sciences, 1, 119.

Sanabria-Ríos, D., \& Bretz, S. L. (2010), "Investigating the relationship between faculty cognitive expectations about learning chemistry and the construction of exam questions", Chemistry Education Research and Practice, 11(3), 212-217.

Steel, S. (2012), "Recovering Ancient and Medieval Contemplative Taxonomies as an Alternative to Bloom's Taxonomy of Educational Objectives", Paideusis. 20. 46-56.

Tabriz, S. \& Rideout, G. (2017), "Critical Pedagogy as an Application of Active Learning", Canada International Conference on Education (CICE). June 27-30, 2017.University of Toronto: Toronto, Ontario, Canada

Tuimur, H. N. E., \& Chemwei, B. (2015), "Availability and Use of Instructional Materials in the Teaching of Conflict and Conflict Resolution in Primary Schools in Nandi North District, Kenya", International Journal of Education and Practice. 3(6), 224-234. 